\title{
TERRITORIALIDADE E INSTITUCIONALIDADE DAS DESIGUALDADES SOCIAIS NO BRASIL. POTENCIAIS DE RUPTURA E DE CONSERVAÇÃO DA ESCALA POLÍTICA LOCAL
}

\author{
Iná Elias de Castro*
}

\section{RESUMO:}

Tendo como questão central o problema da contradição entre a persistente desigualdade social e sua convivência "com uma representação homogênea que os brasileiros possuem de si mesmos", este trabalho enfoca a dimensão política do território e das suas instituições, recuperando o município como sujeito político e objeto de análise. O contexto atual do universo municipal brasileiro, afetado pelas condições institucionais da descentralização e da democracia participativa, estabelecidas na Constituição de 1988, define marcos importantes para uma reflexão sobre as lógicas espaciais da ação individual e coletiva. A análise é feita em dois planos: conceitual, a partir de alguns supostos da teoria da estruturação de Giddens e das discussões recentes do "novo institucionalismo"; empírico, explorando informações selecionadas sobre os Conselhos e os Consórcios municipais e outros recursos institucionais capazes de constituir indicadores das condições de diferenciação do universo municipal brasileiro.

\section{PALAVRAS-CHAVE:}

Municípios, desigualdade sócio-espacial, instituições, teoria da estruturação, conselhos e consórcios municipais.

\section{ABSTRACT:}

Taking as a central question the problem of the contradiction between the persistence of the social inequality and its simultaneity with "the homogeneous image that Brazilian people have of themselves", this paper is focused on the political dimension of the territory and its institutions, recovering the municipalities as a political actor and object of analysis. The current context of the ensemble of all Brazilian municipalities, established by the constitution of 1988, was affected by institutional constraints of decentralization and also by the growth of popular participation in the democratic process, and defines an important landmark for reflections about the spatial logic of individual and collective action. The analysis is done in two levels: the conceptu alone, using someconcepts from Giddens's theory of structuration and also from recent debates on the "new institutionalism"; the empirical one, using selected data about municipal councils and consortia and other institutional resources which can serve as indicators of the conditions of differentiation within the Brazilian municipal emsemble.

\section{KEY WORDS:}

Municipality, social and space inequality, institution, theory of structuration, municipal councils and consortia.

\section{Introdução}

Se é possível identificar nas sociedades nacionais um traço peculiar que as distingue, no Brasil este traço reside na contradição entre a persistente desigualdade social e sua convivência "com uma representação homogênea que os brasileiros possuem de si mesmos" (Chaui, 2000:7). Sendo aceito que, no processo histórico de formação de uma representação de si mesma, cada sociedade define um ethos que se institucionaliza e delineia traços duradouros, no Brasil podemos afirmar que este ethos é o da desigualdade. Esta é sutilmente dissimulada no imaginário social pelo 
mito fundador da mistura de raças, da generosidade da natureza e da cordialidade do seu povo (Castro, 1997), apesar de este ser um dos países de mais elevada concentração de renda do mundo e de fortes disparidades regionais.

A territorialidade dessa desigualdade desafia a geografia a enfrentar a tarefa nada simples de contribuir para a compreensão da gênese dos processos que a produz e cristaliza. Diversos são os caminhos e as possibilidades. A escolha deste trabalho recai na dimensão política do território e nas suas instituições. Esta escolha recupera o município como um recorte carregado de valor, um objeto de investigação de conteúdo material e imaterial, pleno de significado. Neste sentido, o objetivo aqui proposto é demonstrar a pertinência do município como sujeito político e objeto de análise. O que permitirá identificar o seu potencial para desencadear processos de ruptura ou para reforçar os processos estruturadores das desigualdades.

Os municípios brasileiros são recortes territoriais que definem unidades políticas de gestão local. Eles possuem atribuições específicas de governo, de legislação, de regulação do uso do solo urbano, cobrança de impostos e de prestação de diferentes tipos de serviços à população residente como saúde, educação fundamental e assistência social etc. Neles se materializa a institucionalidade da política mais próxima do cidadão, onde podem se desenvolver os fundamentos para o fortalecimento da democracia representativa e participativa ou, ao contrário, podem ser gestados os elementos de rupturas no processo de construção de uma ordem democrática. Mas, eles são também continentes dos interesses e das relações das sociedades locais. Nesta dimensão, eles podem ser o espaço que favorece o fortalecimento dos vínculos horizontais, a solidariedade social e o desenvolvimento do capital social (Putnam, 1996). Mas, podem ser também o espaço de controle e de domínio político de oligarquias conservadoras, com suas estratégias de resistência às transformações necessárias para uma maior justiça distributiva no país.

O contexto atual do universo municipal brasileiro foi afetado pelas condições institucionais da descentralização e da democracia participativa, estabelecidas na Constituição de 1988. Essas condições definem marcos importantes para uma reflexão sobre as lógicas espaciais da ação individual e coletiva. A descentralização promoveu a reorganização dos poderes territoriais no país mediante a reformulação da estrutura federativa. Isto possibilitou a soberania dos níveis federais inferiores ao estado central e criou as condições para a reconfiguração de espaços políticos institucionais, como os municípios, espaços de disputa de interesses que são territorializados.

A questão da dimensão espacial da resistência das desigualdades sociais no país sugere um encaminhamento que focaliza as escalas institucionais locais e as diferenças que elas exprimem, mesmo num quadro de isonomia legal. Neste sentido, a análise é feita em dois planos. O primeiro, conceitual, parte de alguns supostos da teoria da estruturação de Giddens (1984) e das discussões recentes do "novo institucionalismo" (Amin e Thrift, 1994; Théret, 2000). Com Giddens é possível preliminarmente apontar o papel dos locais de assegurar boa parte da "fixidez" subjacente às instituições, além das propriedades dos sistemas sociais como simultaneamente facilitadores e coercitivos em contextos de espaço e tempo. As instituições, por sua vez, moldam as relações sociais pelas normas e procedimentos organizacionais, os quais estruturam os comportamentos porque, paralelamente, moldam a identidade, o poder e a estratégia dos atores (Putnam, 1996; Clingermayer e Feiock, 2001). As instituições são também moldadas pela história, ou seja, são constituídas pelas organizações mas também pelos interesses e objetivos dos atores sociais que conduzem estas organizações em direção a fins específicos. Com base nesses supostos, elaboramos os marcos explicativos para a pertinência do recorte federativo municipal 
brasileiro como espaço político institucional e como objeto de investigação útil na tentativa de compreender as complexas dimensões da resistência das desigualdades no país.

O segundo plano da análise propõe uma abordagem do universo municipal brasileiro através de informações estatísticas disponíveis sobre os recursos intitucionais à disposição das administrações locais. A expectativa é que essas informações, reinterpretadas a partir da matriz conceitual proposta, possam acrescentar elementos novos que auxiliem na compreensão dos mecanismos de reprodução das desigualdades, indicadas acima.

As considerações que se seguem estão organizadas em três partes. Na primeira apresento, de modo sucinto, alguns pontos de partida conceptuais que considero úteis à análise do problema da desigualdade social e sua dimensão espacial. Ainda nessa parte, o município é apresentado como uma escala política institucional e como recorte federativo, condições que acredito lhe conferem consistência como objeto de investigação para a geografia. Na segunda, exploro algumas informações selecionadas aos Conselhos municipais - organizações criadas para assessoria e controle da administração pública - e aos Consórcios municipais - associação cooperativa entre municípios - assim como outros recursos institucionais capazes de constituir indicadores das condições de diferenciação do universo municipal brasileiro. A terceira parte contém uma interpretação possível dos resultados obtidos, tendo em vista a perspectiva conceptual escolhida e as possibilidades de ir um pouco mais adiante, respondendo à questão implícita, de caráter mais geral, sobre as possibilidades empíricas de uma abordagem geográfica das relações entre sociedade, território e desigualdade.

\section{Estruturação, instituições e municípios}

Pensar a organização da sociedade em seu espaço de vida impõe uma reflexão sobre a dinâmica complexa na qual as mudanças e resistências se confrontam em permanência e devem ser consideradas axiologicamente. É neste sentido que qualquer perspectiva conceitual, utilizada para compreender os elementos que se entrecruzam na teia de relações que conduzem tanto à materialidade visível do território como aos valores simbólicos a ele atribuídos, deve considerar esta dualidade entre os agentes da transformação e da resistência no tempo / espaço das sociedades.

No caso do município brasileiro é ainda fundamental acrescentar uma outra possibilidade de análise: aquela que incorpora a noção de escala como referência da necessária articulação entre os três níveis da federação brasileira. Na menor escala do federalismo brasileiro, o recorte municipal define uma realidade territorial, social e histórica e compõe um conjunto fortemente diferenciado que reflete as muitas desigualdades do país. Estas diferenças desafiam visões unívocas e abordagens que não consideram o fato de a sociedade viver no município e também nele organizar as esferas de ação para realizar seus interesses, tornando-o um espaço político por excelência, onde resistência e mudança encontram-se em permanente interação.

Essa abordagem supõe incorporar a dimensão complexa do mundo social e a dialógica da organização que, segundo Morin (1996:180), é ao mesmo tempo menos e mais que a soma das suas partes. Menos porque as organizações estabelecem coações que inibem algumas das potencialidades das suas partes. Nas organizações sociais, coações jurídicas, políticas, militares etc. fazem com que muitas das potencialidades individuais sejam inibidas. Porém, Morin acrescenta, o todo organizado é ao mesmo tempo alguma coisa a mais do que a soma das partes porque faz surgir qualidades que retroagem às partes. Como ocorre com a existência de uma cultura, de uma linguagem, de uma educação, propriedades que só podem existir no nível do todo social, mas recaem sobre as partes para permitir o desenvolvimento da mente e da inteligência dos indivíduos. 
Esta dialógica, mesmo que formulada de outro modo, está também presente na teoria da estruturação de Giddens (1984), o que a torna um recurso adequado para uma problemática focada no território municipal na medida em que ela se propõe incorporar, sem dissociar, as duas dimensões fundadoras da sociedade: a ação e a estrutura. Esta duplicidade permite trazer para o campo de análise os conteúdos materiais e institucionais do território, bem como a dimensão social da ação, organizadora e ao mesmo tempo submetida às suas instituições.

A proposta de Giddens para a teoria da estruturação é importante por indicar os limites explicativos ou, como ele mesmo declara, as deficiências do consenso ortodoxo. Neste sentido, o autor é sensível às escolas de pensamento que enfatizam o caráter ativo e reflexivo da conduta humana e rejeitam a perspectiva que vê o comportamento individual como resultado de forças que os atores não controlam nem compreendem.

Sua tarefa, no entanto, não é negar nem uma ou outra dessas tendências, mas, ao contrário, propor uma formulação do alcance da teoria social em geral, ou seja, compreender a agência humana e as instituições sociais. Para ele, a questão do dualismo entre indivíduo e sociedade, ou entre ator e sistema social, não era suficiente para compreender o fluxo dinâmico da vida social. Esta não deve ser vista apenas como a sociedade de um lado e o produto indivíduo do outro, mas como uma série de atividades e práticas que exercemos e que ao mesmo tempo reproduzem instituições mais amplas. Neste sentido, mais do que centrar as reflexões para uma teorização sobre os conceitos de indivíduo ou sociedade, Giddens tomou como objeto central das ciências sociais a idéia de práticas sociais recorrentes. Ele concebe a estrutura como um fluxo de ações individuais que pode ser relacionado com os atributos de autoconsciência e a sociedade como um complexo de práticas recorrentes que criam instituições. "Ou seja, a sociedade somente tem forma e essa forma somente afeta seus membros enquanto estrutura que se produz e reproduz no que eles fazem" (Giddens e Pierson, 2000). Para o autor, apesar da pouca precisão da expressão "teoria social", que ele se propõe, esta tem a tarefa de fornecer concepções da natureza da atividade social humana e do agente humano que possam ser colocadas a serviço do trabalho empírico. "A teoria da estruturação não será de muito valor se não ajudar a esclarecer problemas de pesquisa empírica", acrescenta.

A importância dos fundamentos da teoria da estruturação para a geografia são evidentes por duas razões. Uma remete à possibilidade de superar a prisão conceitual do paradigma marxista que, mesmo tendo enriquecido intelectualmente a disciplina e ampliado seu campo de abstração, submeteu-a à natureza mesma do materialismo histórico, centrada nas questões de classe (Gregory, 1996), tornando o próprio espaço muitas vezes secundário. Além disso, nesse paradigma, as relações sociais em situações de co-presença das escalas locais são sempre vistas como determinadas por fatores mais amplos, estruturais, o que reduziu qualquer possibilidade explicativa de uma perspectiva propriamente geográfica da ação nessas escalas (Castro, 2002). A outra referese à própria sensibilidade de Giddens para o problema das relações de tempo e espaço. Para ele "as propriedades estruturais dos sistemas sociais só existem na medida em que formas de conduta social são cronicamente reproduzidas através de tempo e espaço". Esta sensibilidade para a espacialidade favoreceu a sua reflexão sobre as possibilidades explicativas das escalas diferenciadas e das localizações, ultrapassando os limites dos marcos estruturalistas ou individualistas das ciências sociais.

Em sua teoria da estruturação, ele procura ligar o contingente e o curto prazo às instituições, que perduram em longos períodos de tempo, incorporando às condições de ambos as mediações do que ele mesmo denomina o meio. Nesta noção são incluídas a base física como cenário da interação social e como recurso alocativo do poder humano sobre a natureza e 
também as regionalizações que resultam da diferenciação espaço temporal entre os locais. Para o autor,

“em conjunto com a transformação do tempo, a co-modificação do espaço estabelece um "meio ambiente criado", de caráter distinto, expressando novas formas de articulação institucionais. Essas novas formas de ordem institucional alteram as condições da integração social e sistêmica e mudam, portanto, a natureza das conexões entre o próximo e o remoto no tempo e no espaço" (Giddens, 1984)

Esta referência muito sumária de alguns supostos conceituais da teoria da estruturação de Giddens possibilita encaminhar o problema das instituições como recurso conceitual e empírico, com possbilidade de ampliar a compreensão das diferenças sociais no território.

O ponto de partida aqui é a existência de uma evidente territorialidade nas instituições. Antes de avançar um pouco mais nesta apresentação, é preciso explicitar os significados atribuídos ao termo instituição. Em sentido amplo, designa as regras do jogo numa sociedade. Esta definição, porém, não esgota o papel das instituições na vida social, uma vez que essas regras se exercem por meio das instituições que moldam as relações sociais pelas normas e procedimentos organizacionais, os quais estruturam os comportamentos porque, paralelamente, moldam a identidade, o poder e a estratégia dos atores (Putnam, 1996; Clingermayer e Feiock, 2001). As instituições são também moldadas pela história no espaço, ou seja, são constituídas pelas organizações mas também pelos interesses e objetivos sociais territorializados que conduzem estas organizações em direção a fins específicos (Putnam, 1996). Com relação ao próprio vocábulo instituição, é importante indicar a dupla possibilidade que existe na sua raiz. Esta traz em si tanto o movimento do instituinte, que luta para ser, como aquele do instituído, que luta para permanecer, o que está de acordo com a perspectiva da estruturação de Giddens.
O interesse renovado pelas instituições nas ciências sociais, embora o tema tenha sido importante na economia e na ciência política, decorre do fato de as instituições políticas, econômicas e sociais terem crescido e se tornado mais complexas e com maior disponibilidade de recursos, afetando mais profundamente a vida coletiva e o espaço. Não é possível ignorar, ou minimizar, o fato de que, nas sociedades contemporâneas, muitos dos atores principais são instituições formais, assentadas sobre o aparato legal, dispondo de uma burocracia, o que Ihes confere um lugar preponderante na sociedade (North,1990; March e Olsen, 1997). Para Clingermayer e Feiock (2001) o papel das instituições deriva de três circunstâncias: na primeira, os arranjos institucionais moldam as ações individuais; na segunda, reduzindo as incertezas, as instituições estabelecem premissas para a decisão; na terceira, as instituições propiciam estabilidade nas escolhas coletivas. É preciso ressaltar que estas circunstâncias, assim definidas, não colocam as instituições no mesmo plano ontológico das estruturas. Ao contrário, elas constituem aparatos que moldam e são moldados pelo universo cognoscitivo dos atores sociais.

Com relação ao nosso interesse mais voltado para o espaço, suas diferenças e sua dinâmica, as instituições que definem padrões significativos dos fenômenos sociais não podem ser abstraídas das dimensões territoriais desses fenômenos. É justamente sua ação que resulta na caracterização do "meio ambiente criado". Nesta perspectiva, as contribuições da geografia para a análise institucional tem buscado identificar os complexos institucionais no território, responsáveis por condutas e práticas sociais particulares. Seguindo a argumentação de Allen (1999), os complexos institucionais permitem diferentes arranjos espaciais e refletem os modos de ação possíveis inscritos em cada modalidade e permitem regular, bem como capacitar, a mobilidade através desses arranjos. Para ele, o mais importante é que as práticas que estão incrustadas nos espaços institucionais são compreendidas como 
constitutivas da ação social. Em outras palavras, diferentes complexos institucionais configuram espaços sociais diferenciados.

Esta interpretação da ação das instituições é bem recente na geografia. Na realidade, a incorporação do conceito como ponto de partida operacional para pesquisa na disciplina se fez muito mais pela vertente estruturalista da teoria da regulação, elaborada nas décadas de 70 e 80 , como reação crítica aos fundamentos da teoria econômica neoclássica. Naquela vertente, os pressupostos da interdisciplinaridade, da necessidade de considerar os recortes temporais e espaciais e a historicidade alimentaram importantes correntes da geografia econômica. Porém, o peso da lógica produtiva e acumulativa atribuído às instituições econômicas obscureceu, em muitos trabalhos desta vertente, a potencialidade reguladora do sistema e das instituições sociais, que se expressavam na escolhas dos atores, especialmente aqueles atuantes no sistema político.

$\mathrm{Na}$ perspectiva regulacionista da economia, as instituições desempenham um papel fundamental para a abordagem do espaço geográfico, que é organizado prioritariamente pelas normas impostas pela lógica da produção. No entanto, para compreender a dinâmica da regulação do território era preciso ir além dessa lógica e também interrogar-se sobre as rotinas que definem as especificidades de um lugar em relação a outros lugares e ao sistema produtivo nacional que o engloba (Gilly e Pecqueur, 1995). Ampliando essa perspectiva, Amin e Thrift (1993) introduziram a noção de densidade institucional através de uma apreciação qualitativa sobre a combinação institucional. Foram considerados, ao mesmo tempo, o número e a diversidade das instituições, a intensidade de suas interações, as relações de poder que as estruturam e o sentimento de pertencimento do conjunto dos atores a um empreendimento comum. Mesmo se no caso desses dois autores a identificação dessa densidade teve como finalidade compreender o sistema produtivo local, ela pode também ser útil para compreender outras dimensões da organização social nesta escala.

A questão das desigualdades sociais no Brasil e a proposta de contribuir para a sua compreensão tomando o município como objeto de análise, explicitado no início, requer considerar a perspectiva do espaço da política. Este é balizado pelo conceito de território, no qual encontram-se intrinsecamente incorporadas as noções de poder e de controle. Neste sentido, o território se define e se constitui a partir de relações fundamentalmente políticas, sendo possível perceber, no conjunto de fatores que resultam diretamente da política, a centralidade das dinâmicas territoriais que afetam a organização da base material da sociedade. O território deve ser, portanto visto como continente de um sistema de interesses, na maioria das vezes conflitantes, que são os fundamentos da necessidade da política e das suas instituições para o controle dos conflitos.

No Brasil, pelas suas características constitucionais, o município é um espaço político por excelência. Nascido dos Concelhos no período colonial, ele foi, desde o início da história do país, o recorte territorial definido para o controle da Metrópole sobre os próceres locais e permanece como um recorte de poder local e o nível da administração pública mais próximo do cotidiano social (Bandechi, 1987). Mesmo se o nome município só se tenha afirmado na Constituição Republicana de 1891, o município é, sem dúvida, a unidade de gestão mais antiga do país, apesar da polêmica sobre os limites concretos da sua autonomia (Faoro, 1975; Duarte, 1942). Acredito que os termos dessa polêmica já estejam ultrapassados pelas condições contemporâneas de exigência crescente de participação social nas escolhas da gestão da coisa pública. Esta participação confere visibilidade aos recortes políticoadministrativos locais, tornando-os cada vez mais objeto de disputa de grupos políticos e objetos de conhecimento.

Sendo, na prática, um distrito eleitoral 
informal (Carvalho, 2003), o território municipal está submetido às condições impostas pelas regras da lógica da conservação e do reforço do sistema político eleitoral para os três níveis da federação, nem sempre compatível com uma gestão cuja lógica deveria ser servir à população. Em um regime político representativo, o único meio de acesso às posições de direção do governo local são as eleições concorrenciais, cujo direito de votar e de ser votado deve ser garantido para todos. No entanto, a competitividade que deve garantir o exercício eficaz da dinâmica democrática depende tanto das condições de participação para o exercício dos direitos da cidadania como das características do contexto social (Castro, 2003). Para Santos Júnior (2001),

"é o entrelaçamento entre o sistema legal - como expressão institucional do sistema democrático do governo - e o município que pode elucidar as características particulares da democracia local (no Brasil). Isto por que a relação do cidadão com o sistema legal é mediatizada, em muitos aspectos, pelo município como entidade política e administrativa independente".

Ainda nesta escala, a co-presença permite maior visibilidade dos interesses e da organização social para alcançá-los. As ações dos atores sociais, do poder público ou da sociedade, são mais explícitas, tanto em relação à demanda e à disponibilidade do aparato institucional para a oferta de políticas públicas direcionadas para a população residente. No país, esta visibilidade ampliou-se a partir da Constituição de 1988, quando se iniciou um processo de descentralização federativa das competências de políticas econômicas e sociais. Como resultado, os encargos das Prefeituras foram ampliados, assim como sua autonomia na estrutura federativa, o que lhes permite legislar e ter receita própria, mediante atribuições específicas de alguns impostos. São estas condições que orientaram a seleção de dois conjuntos de informações para a análise proposta da territorialidade e institucionalidade das desigualdades sociais no Brasil.

\section{Novos recursos institucionais para a sociedade local}

Tendo em vista o problema da persistência das desigualdades sociais no país, foram privilegiadas informações que consideramos capazes de fornecer elementos sobre as potencialidades da ação dos atores locais e o modo como estes podem afetar as características estruturais do sistema social e expressar-se no território. Os dados estatísticos utilizados privilegiam, então, algumas informações sobre os Conselhos e os Consórcios, novos recursos institucionais colocados à disposição das sociedades e dos governos locais, a partir do processo de descentralização iniciado com a Constituição de 1988. Outras informações sobre alguns serviços e políticas sociais foram também escolhidos. Estes, mesmo se inspirados nos princípios de isonomia, quando em funcionamento, permitem a expressão de realidades sociais muito diferentes.

Os Conselhos são temáticos, ou seja, i) vinculam-se a políticas sociais específicas como educação, saúde, emprego, criança etc.; ii) prevêem a participação voluntária de representantes de organizações sociais da sociedade civil; iii) são deliberativos, abrangentes e permanentes, nas temáticas às quais estão vinculados e iv) incidem sobre todo o circuito de gestão de uma política pública, desde a formulação até a sua implementação (Gohn, 1998). Os Consórcios, por sua vez, propiciam a associação para otimizar recursos escassos, seja para prestar serviços à população, seja para melhorar condições de infraestrutura ou para as atividades econômicas. Neste sentido, enquanto os Conselhos são importantes por possibilitar a expressão das potencialidades de mobilização da sociedade civil, os Consórcios propiciam a organização e a cooperação horizontais e fortalecem os vínculos interinstitucionais na sociedade local, melhorando as condições de cooperação e de redução das descontinuidades.

Os Conselhos têm responsabilidade de cogestão e de controle face ao poder executivo. Juntamente com o prefeito, ele elabora os planos e ações da gestão local. A Lei Orgânica Municipal define quais são suas competências e seu papel nas decisões e na elaboração do 
Orçamento Municipal. Estes podem ser de dois tipos: a) os Conselhos Populares, encarregados de discutir e organizar a consulta nos momentos de elaboração das políticas municipais e compostos por associações civis, que são organizações autônomas, não subordinadas à administração municipal; b) os Conselhos Setoriais, ligados ao poder executivo municipal e compostos por representantes dos poderes legislativo, executivo e de associações civis e permitem acompanhar o andamento da política municipal em cada setor. Estes são órgãos de consulta e inspeção.
Os Consórcios Intermunicipais são recursos institucionais de outro tipo. Constituem estratégias associativas destinadas a somar esforços para a solução de problemas comuns. Apesar de regulamentados desde a Constituição de 1937, foram as condições de descentralização e maior autonomia dos municípios como entes federativos, definidas na Constituição de 1988, que vêm possibilitanto a ampliação desta prática cooperativa (Fontes 2001). As maiores atribuições da gestão municipal têm colocado desafios para as prefeituras,

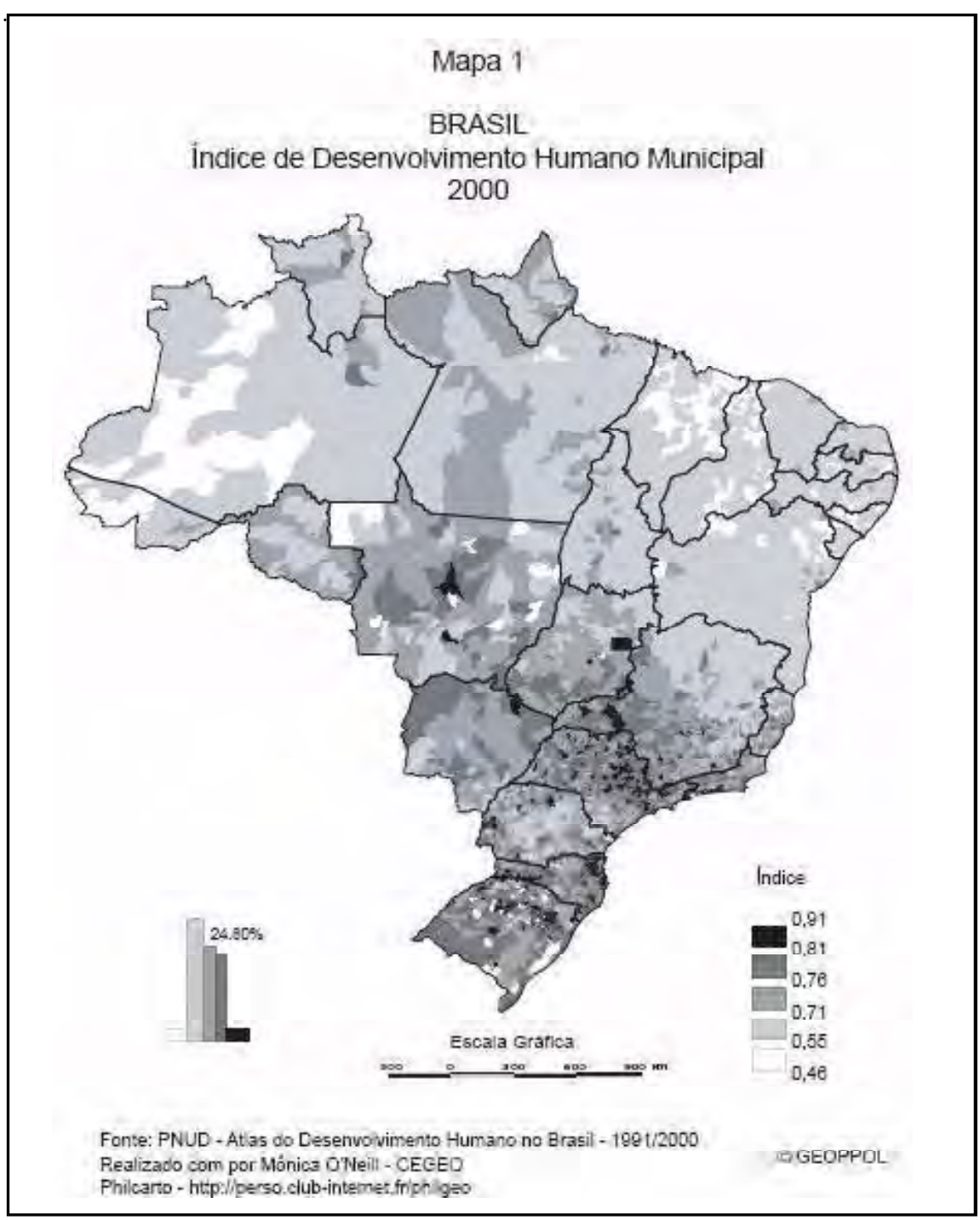


que percebem, em algumas formas de associação com outras, mecanismos institucionalizados de cooperação e troca, capazes de potencializar recursos escassos e alcançar uma gestão mais eficiente.

Os Consórcios têm, portanto, como objetivo superar dificuldades comuns de municípios vizinhos nos campos da administração, assistência técnica, difusão de informações, treinamento de pessoal, prestação de serviços de saúde e de educação. Eles constituem instrumentos destinados a preencher as lacunas nas dificuldades da gestão na escala local, superando-as e ampliando o leque de possibilidades para uma ação governamental mais eficiente.

A disponibilidade desses novos recursos podem estimular ou mesmo fortificar a cooperação interinstitucional horizontal, isto é, entre os municípios. A descentralização federativa para as competências políticas, econômicas e sociais aumentaram e deram grande visisibilidade social aos encargos municipais. Isto tornou o território do município uma arena concreta na qual a sociedade local adquire cada vez mais visibilidade como ator com interesses e instrumentos para atingi-los. São estas condições que guiaram a escolha de dois conjuntos de informações ${ }^{1}$ para a analise proposta.

Antes de passar às informações indicadas acima, quero indicar, de modo muito sucinto, a partir dos mapas de distribuição dos indicadores de desenvolvimento humano e de anos de estudos de pessoas de mais de 25 anos de idade, abaixo, o padrão mais geral da distribuição territorial de algumas características das diferenças sociais no território brasileiro.

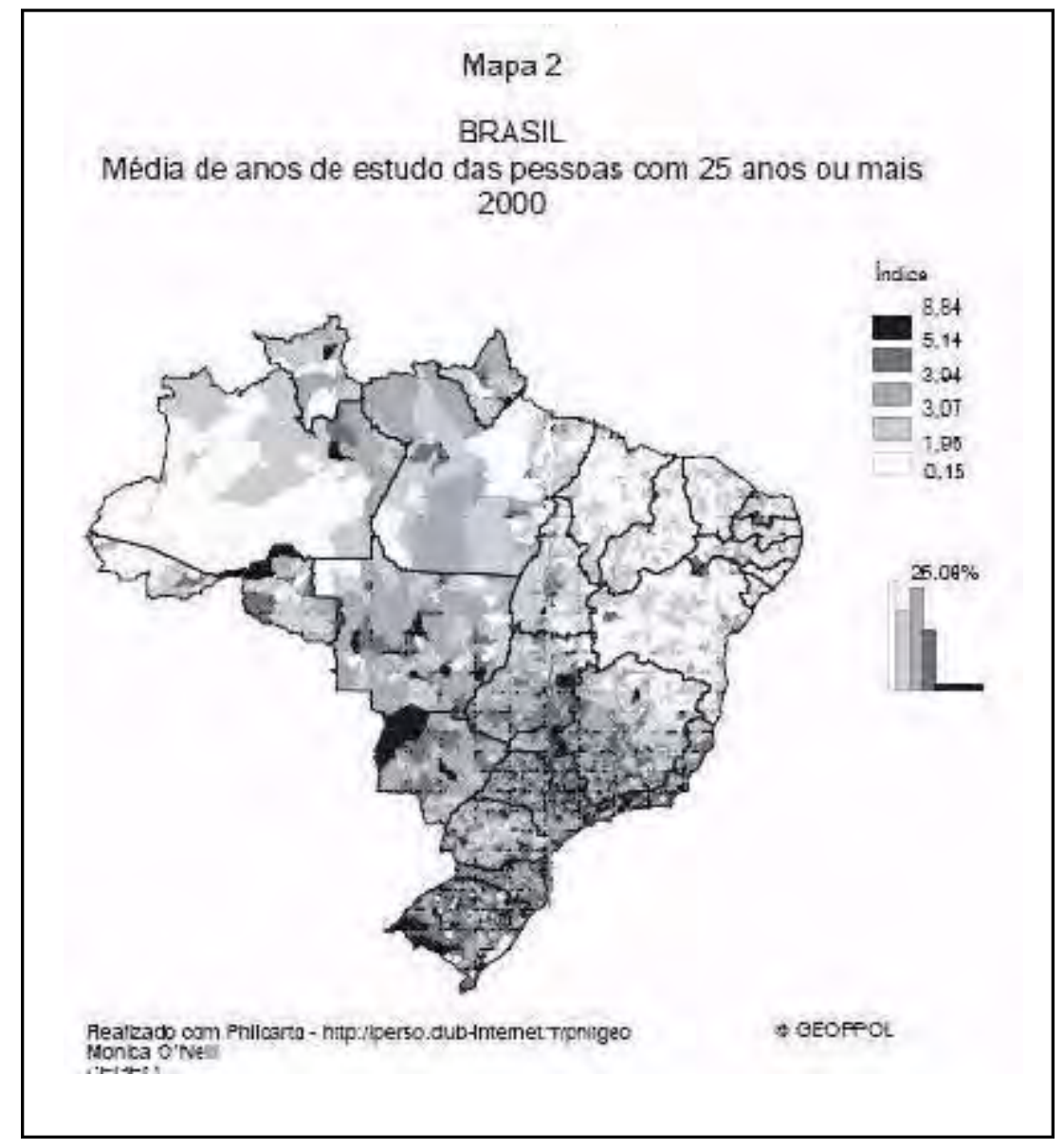


As duas distribuições mostram uma clara divisão Norte-Sul. Mesmo se a grande extensão dos municípios da Amazônia distorcem a representação cartográfica que utiliza métodos coropléticos, é possível afirmar que após muitas décadas de políticas públicas para o desenvolvimento regional, os "dois Brasis" de Jacques Lambert (1959) ainda resistem. Este modo de diferenciação social e espacial forma o quadro de ação para as inovações institucionais da Constituição de 1988. Tomei então como ponto de partida para a análise da suposição de que a isonomia da norma legal deve confrontar-se com instituições que se territorializam e que, nesta condição, agem de forma diferente em territórios diferenciados. Analisando o universo municipal brasileiro e, consequentemente, todo o território do país sob esta ótica, é possivel inferir que a possibilidade formal de as municipalidades criarem Conselhos ou de se associarem em Consórcios não será aproveitada da mesma maneira em todo o território nacional.

Para avaliar a resposta aos novos dispositivos institucionais e as possibilidades de diferenciação pelos efeitos da localização e do tamanho da população do município, foram separadas as informações para os anos 1999 e

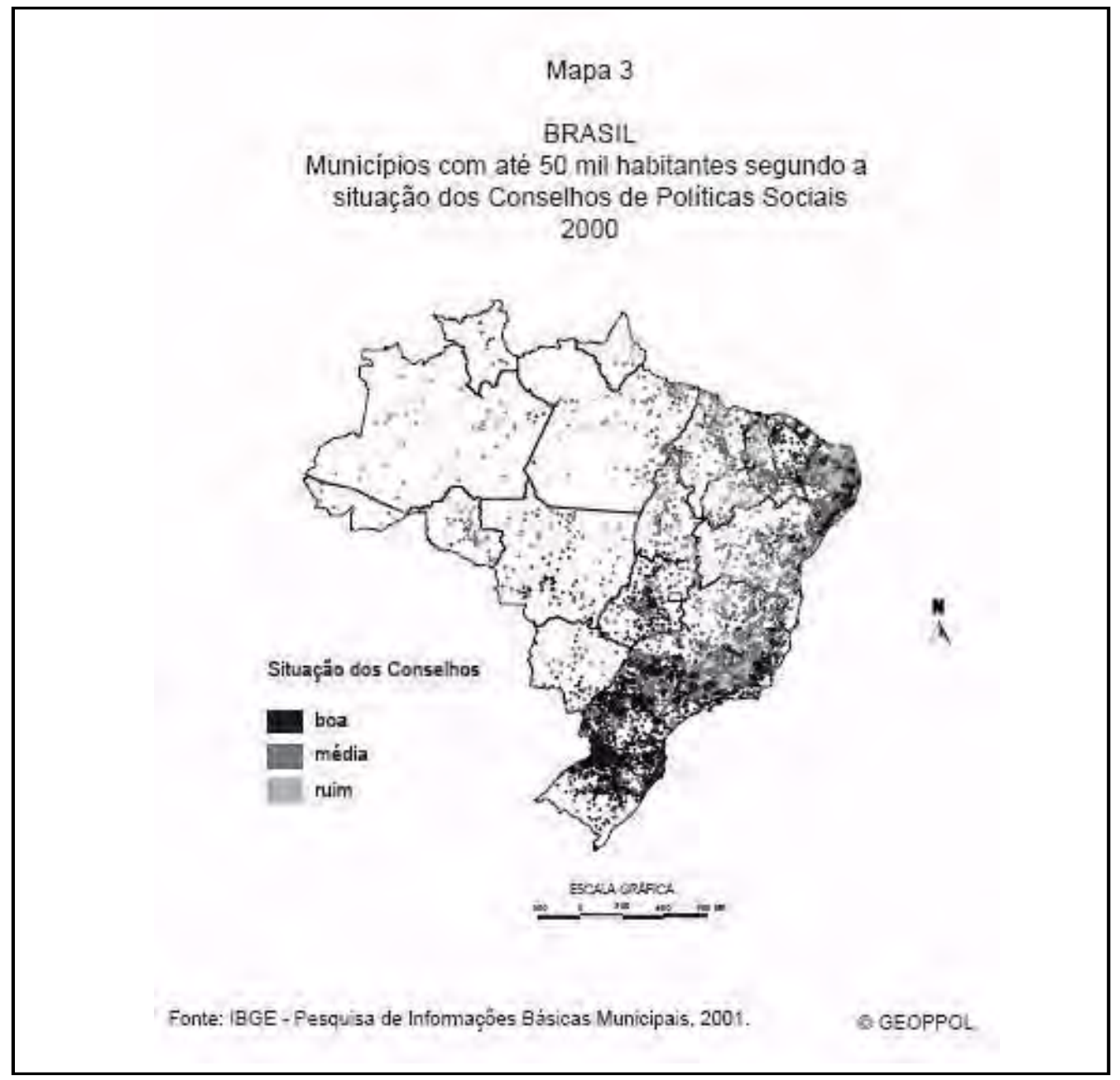


2000 sobre os Conselhos de Política Social e os Consórcios de Saúde, de acordo com cada uma dessas condições. Foram vistos inicialmente os Conselhos municipais para políticas sociais, indicadores importantes da capacidade de mobilização da sociedade local e das prefeituras para a implementação dessas políticas. Como já foi indicado mais acima, os Conselhos são órgãos colegiados, cujos integrantes podem fazer parte tanto da sociedade civil quanto do setor governamental, tendo como funções o estabelecimento de diretrizes para a formulação de políticas públicas setoriais. Foram aqui selecionados os Conselhos de educação, assistência social, da criança e do adolescente e de emprego e trabalho, utilizando os seguintes aspectos que a pesquisa Perfil dos Municípios Brasileiros do IBGE, de 2001, disponibiliza: se o município tem Conselho; se está instalado e regulamentado; se é deliberativo; se é paritário; se administra fundo municipal e com que freqência o conselho se reune ${ }^{2}$.

O mapas a seguir permitem explorar um pouco mais as diferenças encontradas na distribuição dos Conselhos nos municípios até 50.000 habitantes, os quais englobam $92 \%$ dos municípios e $40 \%$ da população do país.

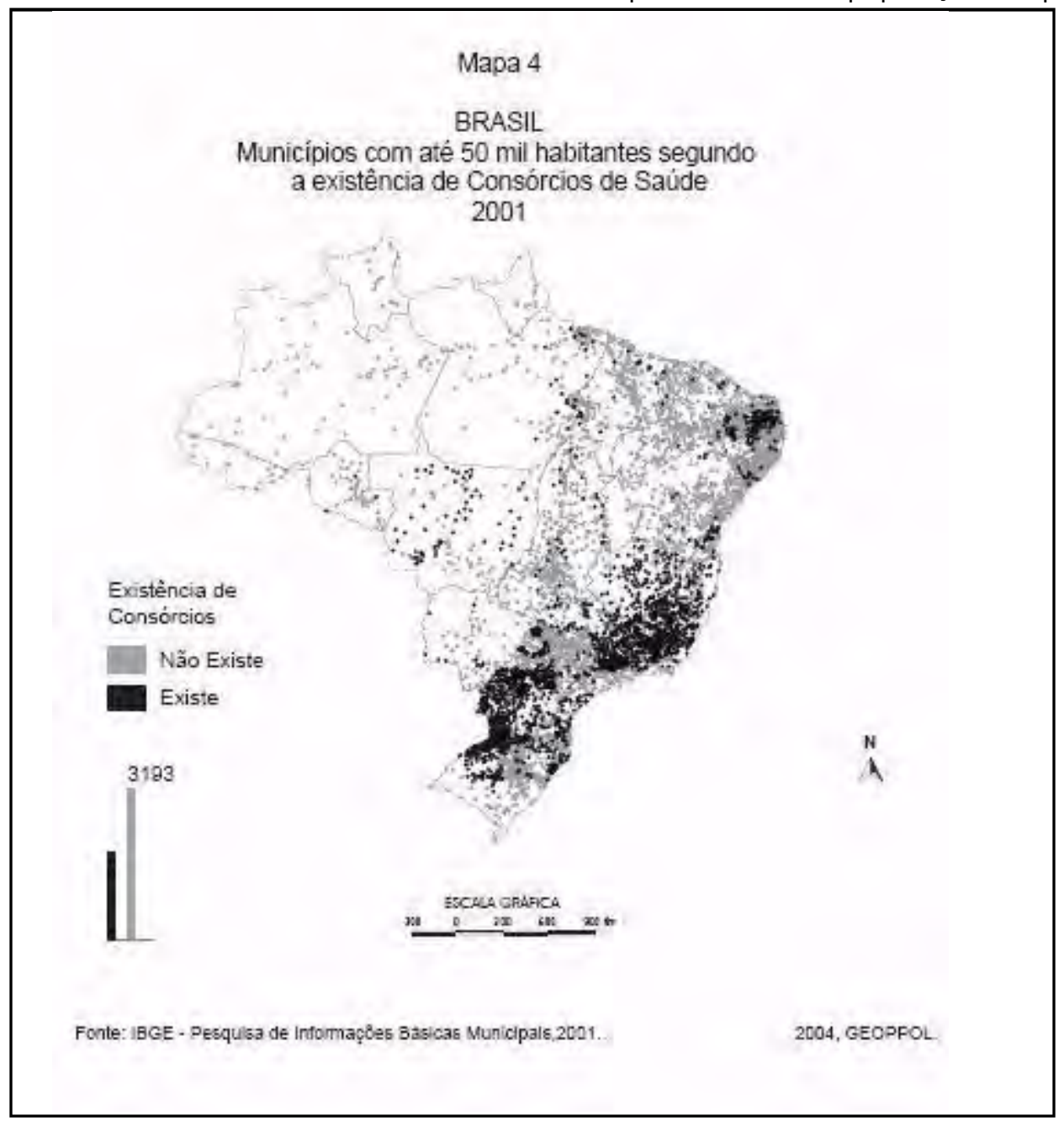


Os mapas se referem a 2001, uma vez que, apesar do crescimento do número de Consórcios e da melhoria dos Conselhos, não houve variação significativa do modelo de distribuição territorial, o que evidencia a forte resistência da divisão Norte-Sul das condições de vida no país. A partir da distribuição no mapa, é possível indicar que a localização é uma condição mais importante que o tamanho da população para que os Conselhos se enquadrem na categoria Ruim de funcionamento e para a existência dos Consórcios. A localização, na realidade, aparece como um fator de diferenciação importante. Neste sentido, para entender as condições desses conselhos, é importante conhecer também onde eles estão e, a partir daí, tentar compreender que características dessa localização podem ter maior poder explicativo.

Como existe obrigatoriedade legal de instalação dos Conselhos em todos os níveis da federação, as diferenças encontradas podem ser consideradas como indicadores das condições de mobilização e participação da sociedade local. Neste sentido, o mapa explicita que os municípios das Regiões Norte e Nordeste possuem condições piores para a mobilização social do que aqueles da Região Sul.

A distribuição dos Consórcios municipais permite ampliar e completar a discussão sobre estes recursos institucionais e o território do país. Para os limites desta apresentação foram selecionados os Consórcios intermunicipais de saúde, que, no ano da pesquisa do IBGE, eram os mais numerosos, englobando quase $40 \%$ dos municípios. Essa distribuição apresenta algumas peculiaridades. Em primeiro lugar, para o conjunto do Brasil, são os municípios com menos habitantes os que mais utilizam este recurso institucional. No entanto, a distribuição regional da frequência analisada não permite uma conclusão simples e direta de que os municípios com menos habitantes, sendo são os que têm menor disponibilidade orçamentária, teriam a cooperação como uma estratégia natural, e portanto esperada
(Castro, Waniez e Brustlein, 2002) ${ }^{3}$. A distribuição regional mostra que os municípios pequenos $^{4}$ das Regiões Sudeste e Sul recorrem muito mais aos consórcios do que aqueles das Regiões Norte e Nordeste. Outra exceção é a Região Centro-Oeste, que possui uma distribuição mais equilibrada entre todas as classes de tamanho dos municípios, o que prejudica uma outra análise apressada sobre a indiferança dos municípios mais povoados em relação a esta forma de cooperação.

A primeira observação que o mapa suscita, além da forte presença nos estados do Sul do país e em Mato Grosso, é a concentração de municípios pequenos com Consórcios de saúde em Minas Gerais e a existência de alguns pontos dispersos na Região Nordeste. Aqui não há como deixar de registrar a forma como o estado de Minas Gerais se destaca do conjunto da federação. Tentaremos discutir melhor estes resultados mais adiante.

Buscando avançar um pouco mais, foram selecionados cinco tipos de aparatos institucionais para o exercício da cidadania: Programa de geração de trabalho e renda, Capacitação profissional, Delegacia de mulheres, Juizado de pequenas causas, Conselho tutelar e Guarda municipal, como já indicados mais acima. Os aparatos foram pontuados e representados no Mapa 5 - Municípios com até 50.000 habitantes segundo a existência de aparatos institucionais para o exercício da cidadania. Novamente a Região Sul se destaca das demais, embora haja diferenciações internas. O oeste da Região e o Estado de Santa Catarina possuem maior concentração desses aparatos do que o conjunto do território regional. Algumas questões emergem desta distribuição. Que condições diferenciam os municípios pequenos de algumas áreas da Região Sul dos de algumas áreas isoladas nas Regiões Norte e Nordeste? Esta diferenciação é relevante para a análise das condições geográficas da desigualdade social? Acredito que a resposta para estas questões esteja mais nos espaços políticos que foram moldados pelas instituições locais ao longo de sua história. 


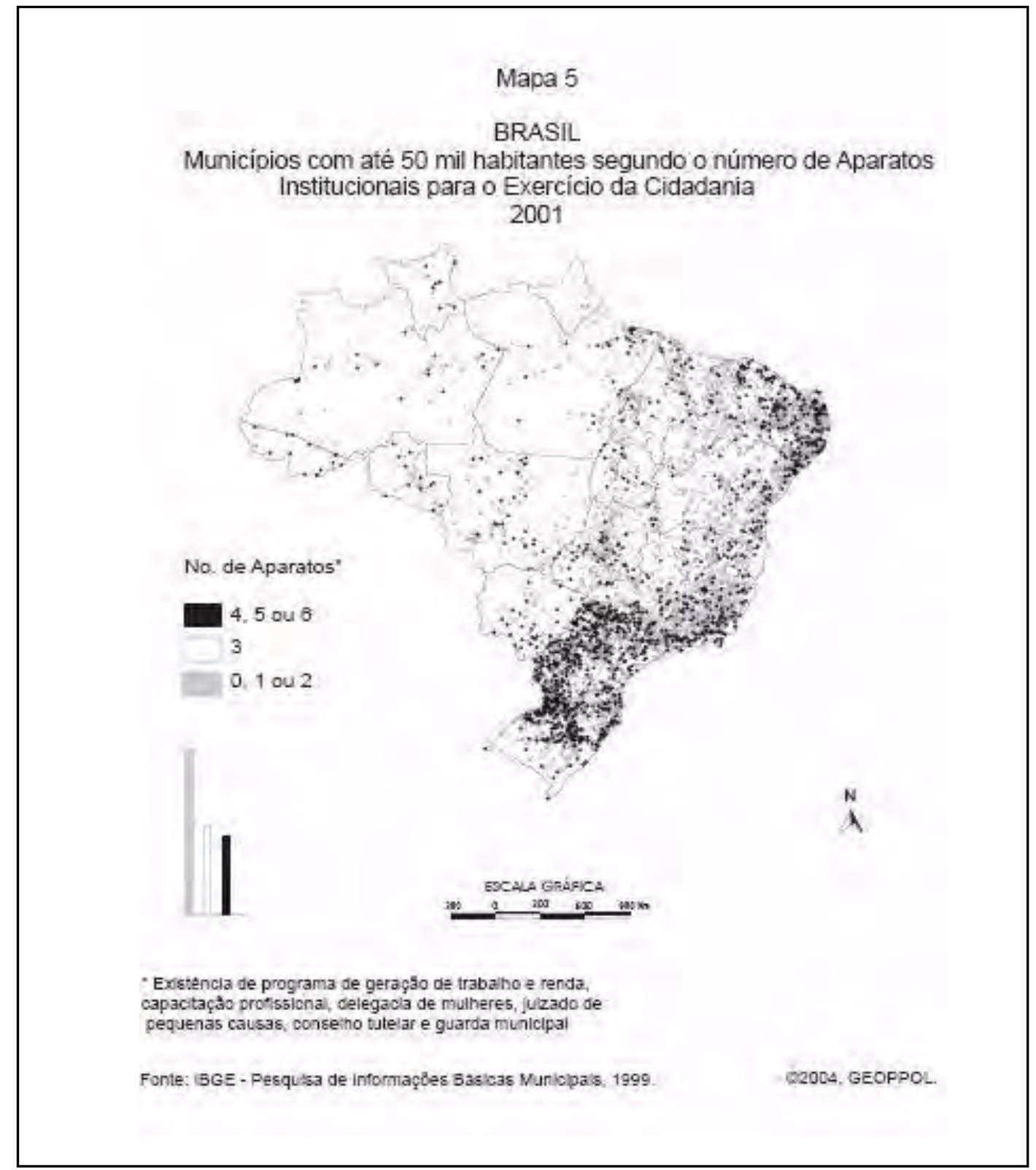




\section{Algumas considerações sobre recursos institucionais, as sociedades locais e as desigualdades}

As diferenças regionais, encontradas nas distribuições apresentadas, obrigam a refletir sobre a recorrência do problema das condições históricas de ocupação do território brasileiro e das descontinuidades produzidas. A diferença entre o Sul e o Norte e Nordeste é bastante sugestiva das diferenças do processo histórico de ocupação em cada uma destas regiões. Acreditamos que a maior participação social nos municípios localizados na primeira, em contraste com a fraqueza nas duas outras, reflete as marcas daquelas condições de ocupação que produziram mais vínculos sociais horizontais no Sul e mais vínculos verticias no Norte e no Nordeste (Putnam, 1993).

Para o significado de vínculos sociais verticais e horizontais recorro a Putnam (1996). Os primeiros são vínculos de dependência e exploração, resultantes das estratégias de sobrevivência das camadas mais pobres em condições históricas de sociedades civis pouco organizadas, comandadas por atores sociais investidos de autoridade e que ocupam espaços de poder abertos pela fragilidade administrativa e judicial do Estado. A imagem de verticalidade decorre da imposição de cima para baixo das regras e normas de reprodução social. No caso particular de muitos municípios da Região Nordeste, sugiro que a institucionalidade desses vínculos tem conseqüências sobre as condições precárias da participação social na Região.

Os vínculos horizontais, ao contrário, são aqueles capazes de criar e fortalecer instituições que favorecem a organização de interesses na base da sociedade. Esses vínculos criam as condições favoráveis à cooperação e à competição e possibilitam as ações estruturantes nas quais a igualdade política, a solidariedade, a confiança e a tolerância são essenciais. As condições originais de ocupação da Região Sul, marcadas pelo isolamento físico, pela organização fundiária em pequenas propriedades, pelo trabalho familiar e pela necessidade de solidariedade para a solução de problemas comuns frente à ausência de serviços que deveriam ser prestados pelo Estado, produziu as condições sociais favoráveis à participação social, sobretudos nos territórios destinados aos imigrantes estrangeiros, atraídos pelas possibilidades de acesso à terra e ao trabalho livre.

Há vasta bibliografia histórica, geográfica e sociológica sobre esta dimensão da diferença regional no país e não é necessário recuperar estas informações, bastante conhecidas. O sentido de apresentá-las de forma tão sintética é apontar uma direção possível para a interpretação da localização como uma das condições das diferenças encontradas entre os municípios. Esta direção permite encaminhar o que considero a resposta mais apropriada para a dupla questão da localização explicitada acima. Nesta perspectiva, a existência de um número bem maior de pequenos municípios com condições boas de funcionamento dos Conselhos de políticas sociais na Região Sul, em contraste com a pequena proporção destes nas Regiões Norte e Nordeste, deriva muito mais das marcas do processo histórico nos vínculos sociais em cada umas destas Regiões do que de uma aleatoriedade na distribuição dos municípios com esses Conselhos. Ou seja, os conteúdos materiais e simbólicos do espaço são recursos à disposição dos atores sociais (Castro, 1997, 2001).

Assim, retomo a suposição explicitada no início sobre a necessidade de a isonomia da norma legal confrontar-se com instituições que se territorializam e, nesta condição, atuam de modo desigual em territórios socialmente diferenciados. Mesmo que os recursos institucionais de participação e de controle da gestão do poder público colocados à disposição da sociedade sejam os mesmos, as formas de apropriação destes recursos pelas sociedades locais são diferenciadas e, consequentemente, os resultados alcançados são muito diferentes.

No entanto, é preciso destacar a exceção no estado de Minas Gerais, onde há grande 
concentração de pequenos municípios que participam de Consórcio de saúde. Nesta unidade da federação, a história da ocupação do território se fez a partir do ciclo escravocrata de mineração do ouro e do diamante, e da expansão da pecuária e da cana de açúcar na Zona da Mata. Afinal, este processo histórico foi bem diferente daquele ocorrido nas áreas de ocupação reservadas aos imigrantes estrangeiros do Sul do país, tendo muito mais semelhanças com aquele do Nordeste brasileiro. Neste sentido, não é possível atribuir à força dos vínculos sociais horizontais em Minas Gerais uma maior predisposição para a associação e busca de parcerias entre as prefeituras do estado. Na realidade, o mapa revela o resultado de uma ação deliberada de governo, de implementar uma política pública de saúde, escolhendo como estratégia o estímulo e o apoio aos Consórcios municipais de saúde ${ }^{5}$.

A concentração deste tipo de recurso institucional em Minas Gerais é, neste sentido, um bom exemplo das possibilidades do desiderato político e suas repercussões sobre o território. Esta condição aponta os limites explicativos do processo histórico como uma causalidade exclusiva para o desenvolvimento institucional $^{6}$ e reforça a complexidade do leque de ações possíveis para a construção de espaços sociais.

Se retornamos a Giddens e sua afirmação de que "as propriedades estruturais dos sistemas sociais só existem na medida em que formas de conduta social são cronicamente reproduzidas através do tempo e do espaço". e também à sua noção de "meio ambiente criado", que expressam novas formas de articulação institucional será possível reinterpretar a resistência desse padrão mais geral de desigualdade no espaço brasileiro. Também, a perpectiva dos vínculos socias verticais ou horizontais, já indicados, pode ajudar, uma vez que as formas de interação social que resultam de cada um decorrem das decisões dos atores, também, no tempo e no espaço.

Neste sentido, a resistente desigualdade mostrou-se como um fator interveniente de peso. As informações sobre os recursos institucionais colocados à disposição da sociedade local possuem um conteúdo significativo. Seus modos de funcionamento e de organização encontram-se demarcados tanto pelos limites municipais - base legal da estrutura federativa do país - como pelo ambiente criado ao longo da história. Mas, o município é também uma escala política importante como distrito eleitoral formal para vereadores e prefeitos e informal para deputados federais e para os governadores. Essas condições certamente afetam tanto a existência como a eficácia daqueles recursos institucionais, mesmo se muitos dos Conselhos municipais podem ser cooptados e colocados a serviço de grupos políticos dominantes locais (Costa, 2002). No entanto, se admitimos que não há evidência de que esta é uma faceta particular da realidade de toda política local no país, a perspectiva do conjunto do território nacional pode ser útil. Esta torna possível perceber a articulação entre as escalas local, regional e nacional e acrecentar novos elementos para a análise das desigualdades, que ultrapassam os limites dos particularismos ou de um determinismo estrutural. Nesse sentido, as diferenças no universo dos municípios e o padrão regional de distribuição das informações, quando se considera os vínculos sociais produzidos pelos contextos de tempo e de espaço diferentes, sugerem que há no país localizações que engendram atores mais favoráveis à equidade do que outras.

A finalidade mais importante deste trabalho foi explorar as possibilidades analíticas da relação entre o território e as instituições de participação política locais e os modos através dos quais esta relação ajuda a compreender o problema da resistente desigualdade social e territorial no Brasil. Paralelamente, os municípios foram recuperados como escalas territoriais coerentes para a pesquisa tanto teórica como empírica na geografia. Os recursos institucionais escolhidos tiveram uma dupla motivação: no caso dos Conselhos, pelo 
significado de mobilização social para a participação e controle da gestão do governo local; no caso dos Consórcios, pela capacidade de cooperação institucional. Nos dois casos são evidentes as combinações das ações dos atores operantes no espaço, porém afetados pelo tempo.

Finalmente, as informações municipais selecionadas desempenharam um papel heurístico e deram visibilidade ao complexo encaixamento das escalas nacional, regional e local no país. Essas escalas fundam a territorialidade das ações dos atores sociais e políticos. A articulação entre a isonomia prevista na Constituição federal e as descontinuidades resultantes das ações dos atores nas escalas dos estados e dos municípios são evidências que devem ser consideradas. Em síntese, é possível destacar três assertivas que poderão ser tomadas como pontos de partida para novas discussões: a primeira aponta a localização como bem mais que um mero cruzamento de coordenadas; a segunda permite inferir que a resistente desigualdade regional pode ser vista como resultado do ambiente criado ao longo da história, e a terceira, que deriva do caso de Minas Gerais e de alguns municípios na Região Nordeste, revela as possibilidades abertas para a sociedade, desde que certos recursos institucionais sejam colocados à sua disposição pela ação dos atores políticos e sociais.

\section{Notas}

${ }^{1}$ Fonte: Pesquisa de Informações Básicas Municipais, 2001e Recenceamento Demográfico, 2000 da Fundação IBGE.

2 Para cada um destes aspectos dos Conselhos selecionados foram atribuídos pontos. Somados os pontos, obteve-se um intervalo em que a pontuação mínima foi zero e a máxima 67 . Em seguida, elaborou-se uma classificação nominal da seguinte forma: os municípios que obtivessem pontos entre zero e 25 seriam classificados em situação ruim dos Conselhos para políticas sociais; os que obtivessem uma pontuação entre $26 \mathrm{e}$ 45, situação regular; e os que obtivessem pontuação entre 46 e 67 foram considerados como tendo Conselhos para políticas sociais em uma situação boa. Estas informações sobre os Conselhos de política social já foram apresentadas em outro artigo, Castro, I.E., 2003.
Porém, a análise aqui tem outro objetivo e explora outros ângulos e possibilidades dos dados.

${ }^{3}$ A questão da localização é importante também para as finanças municipais, ver Castro. I.E. et al. ...texto PAL ...

4 Para não sobrcarregar a redação, estamos chamando de municípios pequenos aqueles de população até 50.000 habitantes, sem qualquer outra referência à área ou à renda.

${ }^{5}$ Esta política pública foi elaborada na gestão do Governador Renato Azeredo do PSDB, durante o período 1994-1998, com apoio do Ministério da Saúde e da Organiização Mundial de Saúde OMS.

${ }^{6}$ Esta possibilidade foi reconhecida por Putnam, op. Cit., embora sem muito entusiasmo. 


\section{Bibliografia}

Allen, J. "Spatial assemblages of power: from domination to empowerment". In: Massey, D. et al. (Eds). Human geography today. Blackwell, 1999: 194-218

Amin, A.; Thrift, N. “Globalisation, institutional thickness and local prospects". In: Revue d'Éconmie Régionale et Urbaine, N 3, 1999.

Bandechi, B. O município no Brasil e sua função política. São Paulo, 5ạ Ed. Editora Pannartz, 1983.

Boyer, R.; Saillard, Y. Théorie de la régulation. L'état des savoirs. La Découverte, 1995.

Carvalho, Nelson Rojas, E no início eram as bases, Rio de Janeiro, Revan, 2003.

Castro, I.E.. The problem of scale, Barcelona, Quaderns, 233, 2002, p.24-31.

Castro, I.E. "Imaginário político e território: natureza, regionalismo e representação". in, De Castro.I.E. et al. (Eds) Explorações geográficas. Rio de Janeiro, Bertrand, 1997, p. 155-196.

Castro, I.E., “ Instituições e território. Possibilidades e limites ao exercício da cidadania". Florianópolis, GEOSUL, 2003.

Castro, I.E., "Natureza, imaginário e a reinvenção do Nordeste", in Rosendahl, Z. Et al. Paisagem, imaginário e espaço, Rio de Janeiro, Ed. UERJ, 2001.

Castro, I.E., Waniez, P., Brustlein, V., “Les finances locales comme révélateur de la croissance e des blocages territoriaux au Brésil", PAL, 45,2002.

Chaui, M. Brasil, mito fundador e sociedade autoritária.São Paulo, F.Perseu Abramo, 2000. p.7A.

Clingermayer, J.; Feiock, R. Institutional constraint and policy choice. State University of New York Press, 2001.

Dereck Gregory, Teoria social e geografia humana, in D. Gregory et al. Geografia Humana, Zahar Editores, Rio de Janeiro, 1996, p. 90-122.
Gatrell, J. D. Spatial niches, policy subsistems, and agenda settinf. The case of the ARC. Political Geography, Vol. 17, N 7: 883-897, 1998.

Giddens, A constituição da sociedade, 2Ed., Martins Fontes, 2003, São Paulo, (p. XVIII). ( The constitution of society, 1984)

Giddens, A., Pierson, C. Conversas com Anthony Giddens. In: O sentido da Modernidade, Ed. FGV, Rio de Janeiro, 2000. p. 62

Gilly, J.-P.; Pecqueur, B. La dimension locale de la régulation. In: BOYER, R.; SAILLARD, Y. Théorie de la régulation. L'état des savoirs. La Découverte, 1995. Lambert, J. Os dois Brasis. Rio de Janeiro, INEP, 1959. March,J.G., Olsen,J.P. El redescubrimiento de las instituciones. La base organizativa de la política. México, Fondo de Cultura Económica. 1997.

Morin, E. Sciece avec conscience. Paris, Fayard, 1982.

North, D. Instituciones, cambio institucional y desempeño económico. Mexico, Fondo de Cultura Económica, 1995.

Putnam, R., Making democracy working: civic tradition in modern Italy, Princeton University Press, 1993.

Ribeiro, M. O município na federação. Salvador, UFBA, 1959.

Santos, M.. A natureza do espaço. São Paulo, Hucitec, 1996.

Théret, B. Institutions et institutionnalismes. Vers une convergence de concepcions de l'institution ? in: Tallard, M. et al. (Dir.) Inovations institutionnelles et territories. Paris, L'Harmattan, 2000.

Trabalho enviado em maio de 2005

Trabalho aceito em setembro de 2005 
